\title{
Methodological Aspects of Epidemiological Studies on the Use of Mobile Phones and their Association with Brain Tumors
}

\author{
Lennart Hardell ${ }^{*}, 1$, Michael Carlberg ${ }^{1}$ and Kjell Hansson Mild ${ }^{2}$ \\ ${ }^{1}$ Department of Oncology, University Hospital, SE-701 85, Sweden \\ ${ }^{2}$ Department of Radiation Physics, Umeå University, SE-901 87 Umeå, Sweden
}

\begin{abstract}
Our case-control studies were the first to report an association between the use of mobile or cordless phones and brain tumors; glioma and acoustic neuroma. Criticism of these results has been based partly on results from the Interphone studies conducted under the auspice of the International Agency for Research on Cancer (IARC). Here, we compare study design and epidemiological methods used in our studies and the Interphone studies. We conclude that while our results appear sound and reliable, several of the Interphone findings display differential misclassification of exposure due to observational and recall bias, for example, following low participation rates in both cases and controls and bed-side computer guided interviews of cases rather than blinded interviews of cases and controls. However, as we have presented elsewhere, there seems to be a consistent pattern of an association between mobile phone use and ipsilateral glioma and acoustic neuroma using $\geq 10$ years latency period.
\end{abstract}

Keywords: Acoustic neuroma, cellular phones, cordless phones, case-control studies, methods, Interphone, epidemiology, glioma, microwaves.

\section{INTRODUCTION}

An association between use of wireless phones and brain tumors has been increasingly discussed during the last decade. Such devices were introduced on the market in the early 1980 's but it was not until the late 1990's that the penetration in the society increased dramatically. A number of casecontrol studies have been published, and there seems in a meta-analysis of these studies to be a consistent pattern of an association between mobile phone use and ipsilateral glioma and acoustic neuroma using $\geq 10$ years latency period $[1,2]$. Thus, for glioma latency period of $\geq 10$-years gave odds ratio $(\mathrm{OR})=1.2,95 \%$ confidence interval $(\mathrm{CI})=0.8-1.9$ and for ipsilateral use (same side as tumour) $\mathrm{OR}=2.0,95 \% \mathrm{CI}=$ 1.2-3.4. Contralateral use did not increase the risk significantly, $\mathrm{OR}=1.1,95 \% \mathrm{CI}=0.6-2.0$. Regarding acoustic neuroma $\mathrm{OR}=1.3,95 \% \mathrm{CI}=0.6-2.8$ was calculated using $\geq 10$ years latency period increasing to $\mathrm{OR}=2.4,95 \% \mathrm{CI}=1.1$ 5.3 for ipsilateral use, but for contralateral use no statistically significant association was found; $\mathrm{OR}=1.2,95 \% \mathrm{CI}=0.7$ 2.2. No clear association with meningioma was found [2].

Twelve of the published case-control investigations are a part of the 'Interphone studies'. These were performed in 13 countries and used a common study protocol laid down by the International Agency for Research on Cancer (IARC) and sponsored by industry [3]. According to the contract for these Interphone studies, the funding industry has full access to the publication of results one week before they are publicly available. Some results of these studies have been

*Address correspondence to this author at the Department of Oncology, University Hospital, SE-701 85, Sweden;

E-mail: lennart.hardell@orebroll.se published in individual countries, see below, but we are still awaiting the final results that seem, now to have been delayed for more than one year [4].

Our Swedish studies were among the first to indicate an association between use of cordless phones and brain tumours [1,2,5-9]. At the moment there are partly conflicting results between our studies and the published Interphone studies, although long-term effects do appear similar. It would seem pertinent therefore to compare the epidemiological methods used in our studies with those used in the Interphone studies in order to better understand the apparent differences in the results. The studies are discussed below, after a discussion of the only cohort study that exists in this area.

\section{MATERIALS AND DISCUSSION}

\section{Cohort Study}

Two publications resulted from a Danish cohort study $[10,11]$. The cohort consisted of people that at some time during the thirteen year period between 1982-1995 were registered for the use of mobile phone. According to the first publication following the study in 2001 follow-up continued until 1996 [10]. In that publication results were given for use of analogue (NMT) and digital (GSM) phones, these separate results were not given, however, in the updated publication in 2006 [11].

Results were also given initially for the duration of use of GSM phones. The results recorded 9 persons with brain tumors that had used GSM $\geq 3$ years and in the same group a somewhat increased standardized incidence ratio $(\mathrm{SIR})=$ $1.2,95 \%$ confidence interval $(\mathrm{CI})=0.6-2.3$ was found for brain and nervous system tumors. In the updated publication 
no data were given for duration of use in years. It is to be noted that such data were not reported for NMT phones even in the initial publication [10].

In the latest publication the cohort was followed for seven more years, against the Danish Cancer Registry until 2002. However, the length of time during which mobile phone had been used was not up-dated. The only information that was given was the most general, that is whether or not the cohort member was a user at one point in time; one phone call per week for six months was the initial inclusion criteria. In the calculation of latency, the first year of registration was used, which was usually not equivalent to the total number of years of cellular phone use.

We know that during the first years of the 1980s almost all use of mobile phones was in cars with external antenna. These subjects were thus unexposed to microwaves. No information about that is given. Subjects appear to have been included as exposed although they were not.

More than 200000 (32\%) company subscribers were excluded. In fact, these are the heaviest users and billed 4.5 times higher than laymen in Sweden for example. They started use earlier than others but were included in the "nonuser" group of the Danish population; the reference population.

In the study SIR was calculated to $1.21,95 \% \mathrm{CI}=0.91$ 1.58 for temporal glioma, that is the most exposed area of the brain [11]. This finding was based on 54 persons. This should have been divided into phone type and first use i.e. latency period. There was no information regarding the ear used during phone calls and its correlation with tumor site. In our studies we found most consistent increased risk in the category of $>10$ years use and the development of ipsilateral tumors $[7,8]$.

Another methodological problem is that expected numbers were based on the general population. However, a large part of the population does use mobile phones and/or cordless phones, and this percent was not assessed at all for the study. This method gives an underestimate of the risk. In the group with first use $\geq 10$ years significantly decreased SIR of $0.66,95 \% \mathrm{CI}=0.44-0.95$ was found for brain and nervous system tumors. This is an indication of methodological problems in the study.

Of the subscribers $85 \%$ were men and $15 \%$ were women, this appears to be a very skewed sex distribution. In fact there seems to be a 'healthy worker' effect in the study since SIR was significantly decreased to $0.93,95 \% \mathrm{CI}=0.92-0.95$ for all cancers. Certainly early mobile phone users are not socioeconomically representative for the whole of the Danish population as used for comparison in the study.

The authors cite an article [12] that they claim has raised "methodological issues" about our studies on this subject. However, alhough apparently used as an example, the discussion is in the most general terms and may be applied to any or all case-controls studies. In the article Schüz et al. [11] failed to cite the following statement in the article "Relying on private cellular network subscription as measure of mobile phone use would also have resulted in substantial misclassification because subscribers bear only a modest relation to users and because corporate users were either excluded or included in the unexposed group" $[12,13]$. That is in fact the case in the Danish study $[10,11]$.

Furthermore, the cohort only included persons older than 18 years, and in view of our finding that those starting their mobile phone use before the age of 20 are at higher risk than those who started later [14], this represents another problem with the study and its conclusions.

Finally the authors fail to acknowledge the contribution by the telecom industry to the study [11] as cited in the first publication [10], i.e. TelemarkDanmarkMobil and Sonofom. Two of the authors are affiliated with the private International Epidemiology Institute (IEI) of Rockville, MD, USA, which has contributed financially to the study. Where IEI gets its money from is not declared although a connection with the mobile phone industry cannot be ruled out $[15,16]$. In the application to the Danish national mobile phone programme, that funded part of the study, no mentioning of the involvement or payment of these two consultants was made, a fact that has raised questions.

In summary there are many methodological problems in the study and it is of limited value in its assessment of longterm health effects, as also discussed elsewhere $[17,18]$.

\section{Case-Control Studies}

From the Interphone study group eight publications give results for glioma [19-26] and seven for acoustic neuroma $[24,25,27-31]$. There are several methodological concerns that need to be addressed in these Interphone studies. Our own studies in this area are the largest outside the Interphone group and our methods and results must be compared with the Interphone studies, especially as we were the first to find a consistent pattern of an association between use of mobile phones and brain tumours. Furthermore, in contrast to our studies, the use of cordless phones was not assessed in the Interphone studies, or such details were not presented $[19,22]$.

\section{The Swedish Interphone Studies}

The Swedish part of the Interphone studies may serve as a model of how these studies were performed using the same core protocol as other Interphone studies. Also, since we are familiar with the Swedish medical system for patients with these tumor types, we have chosen to discuss these two studies in more detail in the following analysis. We discuss in some detail the methods and results of these studies on glioma or meningioma [19], and acoustic neuroma [27]. These studies were part of a medical dissertation [32].

Regarding glioma the Swedish Interphone study [19] reported 23 ORs in Table 2 in the article and 22 of these were $<1.0$ and one $\mathrm{OR}=1.0$. For meningioma all $23 \mathrm{ORs}$ were $<1.0$, six even significantly so. These results indicate a systematic bias in the study unless use of mobile phones prevents glioma and meningioma, which is biologically unlikely. It should be noted that several of the overall ORs also in other Interphone studies were $<1.0$, some even significantly so. As an example, in the Danish Interphone study on 
glioma [20] all 17 ORs for high-grade glioma were $<1.0$, four significantly decreased.

In spite of a reported overall decreased risk, an increased risk was found for tumors on the same side of the brain as the cellular phone had been used (ipsilateral exposure) [19]. These calculations yielded for glioma $\mathrm{OR}=1.6,95 \% \mathrm{CI}=$ 0.8-3.4 for $\geq 10$ years time since first regular use. Contralateral use yielded $\mathrm{OR}=0.7,95 \% \mathrm{CI}=0.3-1.5$. The corresponding results for meningioma were $\mathrm{OR}=1.3,95 \% \mathrm{CI}=$ $0.5-3.9$ and $\mathrm{OR}=0.5,95 \% \mathrm{CI}=0.1-1.7$, respectively.

Similarly 23 ORs were presented for acoustic neuroma for various characteristics of mobile phone use in Table $\mathbf{2}$ from the same study group [27]. Eight ORs were $<1.0,13$ were $>1.0$ and two $\mathrm{OR}=1.0$. No OR was statistically significantly decreased or increased in that table. Time since first regular use of mobile phone $\geq 10$ years yielded for ipsilateral use $\mathrm{OR}=3.9,95 \% \mathrm{CI}=1.6-9.5$ and for contralateral use $\mathrm{OR}=0.8,95 \% \mathrm{CI}=0.2-2.9$. Thus, this study confirmed our finding of an association between mobile phone use and acoustic neuroma $[33,34]$.

Both Swedish Interphone studies have some questionable points concerning study participants, statistical methods, and interpretation of the results that are solely the responsibility of the authors $[19,27]$. In the following paragraphs we discuss some of these issues.

Persons aged 20-69 years living in the medical areas of the university hospitals in Umeå, Stockholm, Gothenburg and Lund in Sweden were eligible. The cases consisted of patients diagnosed with primary glioma, meningioma or acoustic neuroma during September 1, 2000 until August 31, 2002. Unmatched controls were recruited from the population registry. For reasons not disclosed, cases with acoustic neuroma living in the Umeå medical region were not included. This is particularly unfortunate because use of analogue phones has been more common in the northern part of Sweden due to better geographical coverage. Considering our previous findings $[33,34]$ of a significantly increased risk of acoustic neuroma it would have been of special value to include cases from that part of Sweden.

Use of cellular telephones was mostly assessed by personal interviews in the Interphone studies. In contrast to our procedure, the interviewer was aware whether they were a case (patient) or a control, thereby potentially introducing observational bias. It is not described how these personal interviews were organized, a tremendous task considering that vast parts of Sweden from north to south had to be covered. In the sparsely populated and extended area in northern Sweden personal interviews must have meant lots of long distance traveling and imposed additional stress on the interviewers. No information was given in the articles on how or if this methodological problem was solved.

According to the provisions of the Interphone study the interviews were extensive and computer aided. It is likely that such an interview creates a stressful situation for a patient with a recent brain tumor diagnosis and operation. These patients, especially under pressure, often have difficulties remembering past exposures and inevitably have problems with concentration and may have problems with other cognitive shortcomings. According to our experience a better option would have been to start with a mailed questionnaire, that can be answered by the patient during a period of more well-being, if necessary this can be complemented by a telephone interview. This procedure has the additional advantage that it can be accomplished without disclosure during the data collection, whether a person is a case or a control.

The diagnosis of tumor type as well as grading is based on histopathology. X-ray investigation or MR alone is insufficient. Of the 371 cases with glioma in the Swedish Interphone study [19] histopathology examination of the tumor was available for $328(88 \%)$ and for $225(82 \%)$ of meningioma. Thus, it is possible that cases without histology confirmation of the diagnosis may have had another type of brain tumor or even brain metastases. Such misclassifications inevitably bias the result towards unity. It is remarkable that 345 glioma cases were stratified according to grade I-IV, although histopathology was available only for 328 cases. In our studies on brain tumors we have histopathology verification of all of the diagnoses.

For analysis of laterality (ie. the risk of brain tumors on the same side or the opposite side the mobile phone was held during phone calls) an interesting approach was applied in the Swedish Interphone studies. The researchers split the cases into two subsets: those with left and those with right side tumors. Controls were randomly allocated to one of these subsets at a 1:1 ratio. Odds ratios calculated within these subsets were then pooled to give an overall estimate. This method is in principle correct for studies with unmatched controls. However, exposure categorization was questionable for ipsilateral but completely faulty for contralateral use of a mobile phone. Subjects were considered exposed if they used the phone on the same or on both sides of the head. On the other hand, if they used the phone on the contralateral side or did not regularly use a mobile phone they were considered unexposed.

Hence the reference category contained subjects using a mobile phone regularly but reported use on the other side of the head, as the tumor was located. Although exposure to microwaves from mobile phone use is substantially lower on the contralateral side, this discrepancy is less pronounced for regions of the brain (the ventricular and subventricular space) where glioma may originate. Therefore, the chosen procedure introduced exposure misclassification which could have biased the results. For contralateral exposure the opposite exposure classification was used. Patients with tumors on the same side as their exposure were considered part of the reference group. This is an obvious methodological flaw because risk for contralateral exposure would have to be decreased by including ipsilateral exposed cases in the reference group.

It should be pointed out that another weakness in the glioma and meningioma study was that for 33 glioma and 8 meningioma cases information on exposure was obtained from relatives, whereas no relatives of the controls were interviewed [19]. According to our experience relatives have 
difficulties in giving information on the use of cellular telephones, especially about the side of the head the phone most frequently used during phone calls.

There are some discrepancies concerning number of cases identified and data in the Swedish Cancer Registry. We used the same criteria for case recruitment from the Swedish Cancer Registry. For example the Cancer Registry contained 469 cases with intracranial glioma cases compared with the 499 in the Interphone study, 337 meningioma cases versus 320 , and 122 acoustic neuroma cases compared with 160 in the Interphone study $[19,27]$. The study included cases from neurosurgery, oncology and neurology clinics as well as regional cancer registries in the study areas, and there seems thus to be inconsistency with the numbers in the Cancer Registry.

Among the controls in the glioma and meningioma study $282(29 \%)$ refused to participate [19]. Among some of these non-responders a short interview was made and only $34 \%$ reported regular use of a cellular telephone compared with $59 \%$ of the responders. If this discrepancy extends to the total group of non-responders the 'true' percentage of mobile phone users in controls would be approximately $52 \%$. Hence this figure would be lower than in glioma (58\% exposed) and acoustic neuroma cases $(60 \%)$. Only for meningioma with $43 \%$ exposed cases a lower percentage was reported, however, considering the sex ratio (women:men) for meningioma of about 2:1 a lower percentage of mobile phone users has to be expected due to the lower rate of users among women. It should be noted, however, that a similar procedure in another Interphone study yielded similar results regarding mobile phone use among responders and non-responders [26].

It was discussed in the medical dissertation [32] that: 'Our Swedish study, that includes a large number of longterm mobile phone users, does not support the few previously reported positive findings, and does not indicate any risk increases neither for short-term or long-term exposures.' Considering the methodological shortcomings and that in contrast to the cited assertion of 'a large number of longterm users' the study subjects included only 25 glioma and 12 meningioma cases with long-term use, its conclusion seems to be going a long way beyond what can be scientifically defended.

It should be pointed out that one of the authors (Ahlbom) had stated, before the study started, that an asserted association between cellular telephones and brain tumors is 'biologically bizarre' [35]. This statement might occlude him from objectivity in his own investigation. The REFLEXstudy indicates that there are biological mechanisms that could link exposure to the development of diseases such as brain tumors [36].

\section{General Comments}

In Table 1 methodological aspects on the Hardell et al. and Interphone studies are presented. Several issues may be discussed.

Both sets of studies had the case-control design, included both women and men and were performed during a similar time period, except for the first Hardell et al. study that in- cluded cases and controls for the time period 1994-1996 $[5,6]$. Our studies included cases and controls aged 20-80 years, whereas the Interphone studies included various age groups, mostly the age groups $20-69$ years or 30-69 years, c.f. [1].

In the Interphone studies deceased cases were included with interviews of relatives, but only living controls. This might have introduced recall bias since it is probably difficult for relatives to know mobile phone habits, ear used during phone calls, type of phone etc. In our studies only living cases and controls were included. It is unlikely that excluding deceased cases would have biased the results unless use of wireless phones gives decreased OR for deceased cases; to balance an increased OR among living cases.

One large difference between our studies and the Interphone studies was assessment of exposure, as discussed above. We used postal questionnaires that were blinded as to case or control status during assessment of exposure and data coding. The questionnaire was sent home to the cases, in general about two months after the diagnosis. This gave a more relaxed situation for the cases compared with the Interphone studies where mostly bedside interviews were performed during the patients' stay at the hospital, some even newly operated upon.

Obviously in the Interphone studies the case and control status was known during the interviews and processing of data in the computer. Observational bias might have been introduced in these studies since the interviewer knew if it was a case or control that was being interviewed. In contrast, assessment of exposure and all further data processing until statistical analysis was blinded as to being a case or a control in our studies. Assessment of exposure was similar for cases and controls.

It might have been a stressful situation for the cases with bedside interviews in the Interphone studies creating recall bias. In one of the Interphone studies Mini-Mental State Examination was completed by $80 \%$ of the cases and $90 \%$ of the controls [20]. It was concluded that patients scored significantly lower than controls due to recalling words (aphasia), problems with writing and drawing due to paralysis. Certainly these cognitive defects would not be expected to the same extent for patients with acoustic neuroma and clearly in the Swedish Interphone studies the results for acoustic neuroma [27] seem to be more sound and reliable than for glioma and meningioma [19].

We included use of mobile or cordless phone 'any time' in the exposed group and made dose-response calculations based on number of hours of cumulative use. The unexposed group included also subjects with use of wireless phones with $\leq 1$ year latency period.

On the contrary, mobile phone use in the Interphone studies was defined as 'regular use' on average once per week during at least 6 months, less than that was regarded as unexposed including also all use within $<1$ year before diagnosis. This definition of 'regular use' seems to have been arbitrarily chosen and might have created both observational 
Table 1. Methodological Aspects on the Hardell et al. and Interphone Studies.

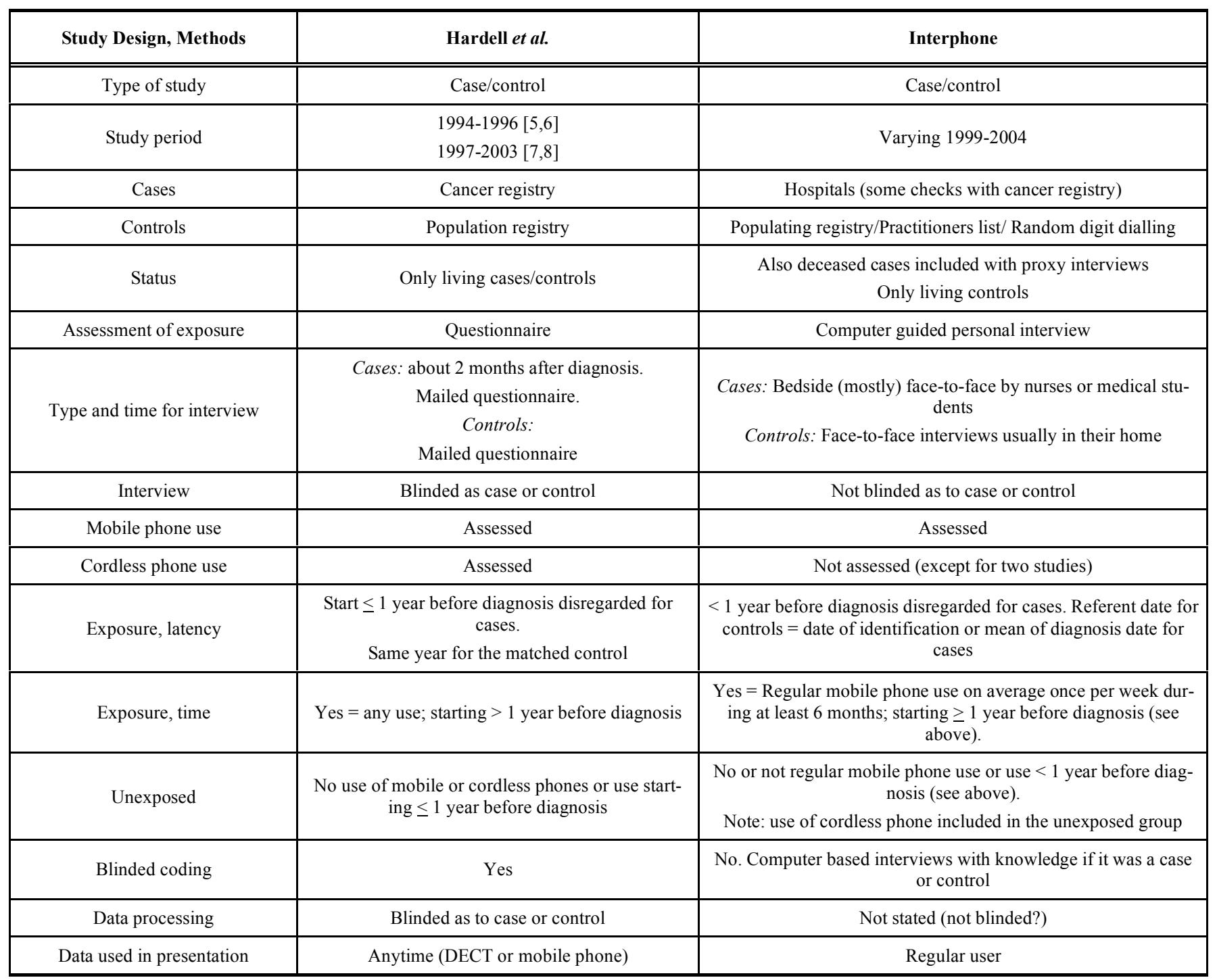

and recall bias in the interpretation of such a vague definition.

Use of cordless phones was not assessed or not clearly presented in the Interphone studies, e.g. $[19,22]$. We found a consistent pattern of an association between cordless phones and glioma and acoustic neuroma [7,8]. It has been shown that the GSM phones have a median power in the same order of magnitude as cordless phones [37]. Moreover, cordless phones are usually used for longer calls than mobile phones $[7,8]$. Including subjects using cordless phones in the "unexposed" group in studies on this issue, as for example in the Interphone investigations, would thus underestimate the risk and bias OR against unity.

In Table 2 we present response rates for cases and controls in the various studies. The case participation was good in our studies, $88 \%$ for cases with benign brain tumours, $90 \%$ for malignant brain tumour cases and $89 \%$ for the controls. On the contrary case participation varied from $37 \%$ to $93 \%$ and control participation from $42 \%$ to $75 \%$ in the Inter- phone studies. Obviously low participation rates for cases and controls might give selection bias and influence the results in the Interphone studies.

Methodological issues in the Interphone studies have been discussed elsewhere [38,39]. It was concluded that the actual use of mobile phones was underestimated in light users and overestimated in heavy users. Random recall bias could lead to large underestimation in the risk of brain tumours associated with mobile phone use. It was further suggested that selection bias in the Interphone study resulted in under selection of unexposed controls with decreasing risk at low to moderate exposure levels.

The Interphone studies have been discussed in letters to the Editor regarding e.g. the German study on glioma and meningioma $[22,40]$, the UK study on glioma $[21,41,42]$, the study on acoustic neuroma in five countries [29,43-45], the Swedish study on glioma and meningioma $[19,46]$, and the Danish study on acoustic neuroma $[28,47,48]$. Thereby similar critique as in this presentation has been made. 
Table 2. Response Rates (Percent) in the Hardell $e$ t al. and the Interphone studies. Numbers of Interviewed Cases is Given. Note that for the Hardell et al. Pooled Results are Given from Previously Published Original Results

\begin{tabular}{|c|c|c|}
\hline Study & \multicolumn{2}{|c|}{ Response (Number and Percent) } \\
\hline - Benign brain tumors & $1254(88 \%)$ & $2162(89 \%)$ \\
\hline - Malignant brain tumors & $905(90 \%)$ & \\
\hline \multicolumn{3}{|l|}{ Lönn et al. (Sweden) 2005 [19] } \\
\hline - Glioma & $371(74 \%)$ & $674(71 \%)$ \\
\hline - Meningioma & $273(85 \%)$ & \\
\hline \multicolumn{3}{|l|}{ Christensen et al. (Denmark) 2004 [28] } \\
\hline - Glioma & $252(71 \%)$ & $822(64 \%)$ \\
\hline - Meningioma & $175(74 \%)$ & \\
\hline \multicolumn{3}{|c|}{ Schoemaker et al. (Five North European countries) 2005 [29] } \\
\hline - Acoustic neuroma & $678(82 \%)$ & $3553(42 \%)$ \\
\hline \multicolumn{3}{|l|}{ Hepworth et al. (England) 2006 [21] } \\
\hline - Glioma & $966(51 \%)$ & $1716(45 \%)$ \\
\hline \multicolumn{3}{|l|}{ Schüz et al. (Germany) 2006 [22] } \\
\hline - Glioma & $366(80 \%)$ & $1494(61 \%)$ \\
\hline - Meningioma & $381(88 \%)$ & \\
\hline - Acoustic neuroma & $45(68 \%)$ & \\
\hline \multicolumn{3}{|c|}{ Lahkola et al. (Five North European countries) 2007 [23] } \\
\hline - Glioma & $1521(60 \%$; range $37-81 \%)$ & 3301 (50\%; range $42-69 \%)$ \\
\hline \multicolumn{3}{|l|}{ Hours et al. (France) 2007 [24] } \\
\hline - Glioma & $96(60 \%)$ & $455(75 \%)$ \\
\hline - Meningioma & $145(78 \%)$ & \\
\hline - Acoustic neuroma & $109(81 \%)$ & \\
\hline \multicolumn{3}{|l|}{ Schlehofer et al. (Germany) 2007 [31] } \\
\hline - Acoustic neuroma & $97(89 \%)$ & $194(53 \%)$ \\
\hline \multicolumn{3}{|l|}{ Takebayashi et al. (Japan) 2008 [26] } \\
\hline - Glioma & $88(59 \%)$ & $196(53 \%)$ \\
\hline - Meningioma & $132(78 \%)$ & $279(52 \%)$ \\
\hline - Pituitary adenoma & $102(76 \%)$ & $208(49 \%)$ \\
\hline
\end{tabular}

\section{CONCLUSION}

Our study group was the first to report a consistent pattern of an association between wireless phones and glioma and acoustic neuroma, whereas this was not found for meningioma. Meta-analysis of all published studies in this area using a reasonable latency period of at least 10 years confirmed this finding for use of mobile phones and ipsilateral 
glioma and acoustic neuroma, but no significant association was found for meningioma [1,2]. Our studies have been attacked by unfounded critique as we have explored in detail elsewhere [37], but also in the publications presenting our case-control studies. Based on a comparison between our studies and the Interphone studies our results seem to be sound and reliable whereas several of the Interphone findings are prone to differential misclassification of exposure due to e.g. observational and recall bias.

\section{ACKNOWLEDGEMENT}

This work was supported by a grant from Cancer- och Allergifonden (Cancer and Allergy Fund).

\section{REFERENCES}

[1] Hardell L, Carlberg M, Söderqvist F, Hansson Mild K, Morgan LL. Long-term use of cellular phones and brain tumours - increased risk associated with use for $\geq 10$ years. Occup Env Med 2007; 64: 626-32.

[2] Hardell L, Carlberg M, Söderqvist F, Hansson Mild K. Metaanalysis of long-term mobile phone use and the association with brain tumours. Int J Oncol 2008; 32: 1097-1103.

[3] Cardis E, Richardson L, Deltour I, et al. The INTERPHONE study: design, epidemiological methods, and description of the study population. Eur J Epidemiol 2007; 22: 647-64.

[4] Microwave News. [cited 2008 March 19] Available from: http://www.microwavenews.com/

[5] Hardell L, Näsman Å, Påhlson A, Hallquist A, Hansson Mild K. Use of cellular telephones and the risk for brain tumours: A casecontrol study. Int J Oncol 1999; 15: 113-6.

[6] Hardell L, Hansson Mild K, Påhlson A, Hallquist A. Ionizing radiation, cellular telephones and the risk for brain tumours. Eur J Cancer Prev 2001; 10: 523-9.

[7] Hardell L, Carlberg M, Hansson Mild K. Pooled analysis of two case-control studies on the use of cellular and cordless telephones and the risk of benign brain tumours diagnosed during 1997-2003. Int J Oncol 2006; 28: 509-18.

[8] Hardell L, Hansson Mild K, Carlberg M. Pooled analysis of two case-control studies on use of cellular and cordless telephones and the risk for malignant brain tumours diagnosed in 1997-2003. Int Arch Occup Environ Health 2006; 79: 630-9.

[9] Hardell L, Hansson Mild K. Cellular telephones and the risk for brain tumours. World J Surgical Oncology 2006; 4: 74. DOI 10.1186/1477-7819-4-74; [cited 2008 March 19]; Available from: http://www.wjso.com/content/4/1/74.

[10] Johansen C, Boice Jr JD, McLaughlin JK, Olsen JH. Cellular telephones and cancer - a nationwide study in Denmark. J Natl Cancer Inst 2001; 93: 203-7.

[11] Schüz J, Jacobsen R, Olsen JH, Boice Jr JD, McLaughlin JK, Johansen C. Cellular telephone use and cancer risk: Update of a nationwide Danish cohort. J Natl Cancer Inst 2006; 98: 1707-13.

[12] Ahlbom A, Green A, Kheifets L, Savitz D, Swerdlow A. Epidemiology of health effects of radiofrequency exposure. ICNIRP (International Commission for Non-ionizing Radiation Protection) Standing Committee on Epidemiology. Environ Health Perspect 2004; 112: 1741-54.

[13] Funch DP, Rothman KJ, Loughlin JE, Dreyer NA. Utility of telephone company records for epidemiologic studies of cellular telephones. Epidemiology 1996; 7: 299-302.

[14] Hardell L, Hansson Mild K, Carlberg M, Hallquist A. Cellular and cordless telephones and the association with brain tumors in different age groups. Arch Env Health 2004; 59(3): 132-7.

[15] Hardell L. From phenoxyacetic acids to cellular telephones: Is there historic evidence of the precautionary principle in cancer prevention? Int J Health Serv 2004;4:25-37.

[16] Hardell L, Walker MJ, Walhjalt B, Friedman LS, Richter ED. Secret ties to industry and conflicting interests in cancer research. Am J Ind Med 2007; 50: 227-33.

[17] Hocking B. Re: Cellular telephones and cancer - a nationwide cohort study in Denmark. J Natl Cancer Inst 2001; 93: 877-8.
[18] Hardell L, Hansson Mild K. Re: Cellular telephones and cancer - a nationwide cohort study in Denmark. J Natl Cancer Inst 2001; 93: 952.

[19] Lönn S, Ahlbom A, Hall P, Feychting M. Swedish Interphone Study Group. Long-term mobile phone use and brain tumor risk. Am J Epidemiol 2005; 161: 526-35.

[20] Christensen HC, Schüz J, Kosteljanetz M, et al. Cellular telephones and risk for brain tumors: a population-based, incident case-control study. Neurology 2005; 64: 1189-95.

[21] Hepworth SJ, Schoemaker MJ, Muir KR, Swerdlow AJ, van Tongeren MJ, McKinney PA. Mobile phone use and risk of glioma in adults: case-control study. BMJ 2006; 332(7546): 883-887.

[22] Schüz J, Böhler E, Berg G, et al. Cellular phones, cordless phones, and the risks of glioma and meningioma (Interphone Study Group, Germany). Am J Epidemiol 2006; 163(6): 512-520.

[23] Lahkola A, Auvinen A, Raitanen J, et al. Mobile phone use and risk of glioma in 5 North European countries. Int J Cancer 2007; 120: $1769-75$.

[24] Hours M, Bernard M, Montestrucq L, et al. Cell phones and risk of brain and acoustic nerve tumours: the French INTERPHONE casecontrol study. Revue d'Èpidèmiologie et de Santé Publique 2007; 55: 321-32, 2007.

[25] Klaeboe L, Blaasaas KG, Tynes T. Use of mobile phones in Norway and risk of intracranial tumours. Eur J Cancer Prev 2007; 16: 158-64.

[26] Takebayashi T, Akiba S, Kikuchi Y, et al. Mobile phone use, exposure to radiofrequency electromagnetic field, and brain tumour: a case-control study. Br J Cancer 2008; 98: 652-9.

[27] Lönn S, Ahlbom A, Hall P, Feychting M. Mobile phone use and the risk of acoustic neuroma. Epidemiology 2004; 15: 653-9.

[28] Christensen HC, Schüz J, Kosteljanetz M, Poulsen HS, Thomsen J, Johansen C. Cellular telephone use and risk of acoustic neuroma. Am J Epidemiol 2004; 159: 277-83.

[29] Schoemaker MJ, Swerdlow AJ, Ahlbom A, et al. Mobile phone use and risk of acoustic neuroma: results of the Interphone case-control study in five North European countries. Br J Cancer 2005; 93: 8428.

[30] Takebayashi T, Akiba S, Kikuchi Y, et al. Mobile phone use and acoustic neuroma risk in Japan. Occup Environ Med 2006; 63: 8027.

[31] Schlehofer B, Schlafer K, Blettner M, et al. Environmental risk factors for sporadic acoustic neuroma (Interphone Study Group, Germany). Eur J Cancer 2007;43:1741-7.

[32] Lönn S. Mobile phone use and risk of intracranial tumors. Medical Dissertation, Karolinska Institute, Stockholm 2004.

[33] Hardell L, Hansson Mild K, Carlberg M. Further aspects on cellular and cordless telephones and brain tumours. Int J Oncol 2003; 22: 399-407.

[34] Hardell L, Hansson Mild K, Carlberg M, Hallquist A, Påhlson A. Vestibular schwannoma, tinnitus and cellular telephones. Neuroepidemiology 2003; 22: 124-129.

[35] Adami HO, Ahlbom A, Ekbom A, Hagmar L, Ingelman-Sundberg M. Opinion - "Experts who talk rubbish". Bioelectromagnetics Society Newsletter 2001; 162: 4-5.

[36] Risk Evaluation of Potential Environmental Hazards From Low Frequency Electromagnetic Field Exposure Using Sensitive in vitro Methods. Final Report. [cited 2008 March 19] Available from: http://www.itis.ethz.ch/downloads/REFLEX_Final\%20Report_171 104.pdf

[37] Hansson Mild K, Hardell L, Kundi M, Mattsson MO. Mobile phones and cancer: Is there really no evidence of an association? (Review) Int J Mol Medicine 2003; 12: 67-72.

[38] Vrijheid M, Cardis E, Armstrong BK, et al. Validation of short term recall of mobile phone use for the Interphone study. Occup Environ Med 2006; 63: 237-43.

[39] Vrijheid M, Deltour I, Krewski D, Sanchez M, Cardis E. The effects of recall errors and selection bias in epidemiologic studies of mobile phone use and cancer risk. J Expo Sci Environ Epidemiol 2006; 16(4): 371-84.

[40] Morgan LL. Re: Cellular phones, cordless phones, and the risks for glioma and meningioma (Interphone study group, Germany). Am J Epidemiol 2006; 164: 292-6.

[41] Morgan LL. Mobile phone use and risk of glioma in adults. Study has many flaws. BMJ 2006; 332: 1035. 
[42] Hardell L, Hansson Mild K. Mobile phone use and risk of glioma in adults: results are difficult to interpret because of limitations. BMJ 2006; 332: 1035 .

[43] Hardell L, Hansson Mild K. Mobile phone use and risk of acoustic neuroma: results of the interphone case-control study in five North European countries. Br J Cancer 2006; 94(9): 1348.

[44] Hocking B. Mobile phone use and risk of acoustic neuroma. Br J Cancer 2006; 94(9): 1350.
[45] Milham S. Mobile phone use and risk of acoustic neuroma: results of the interphone case-control study in five north European countries. Br J Cancer 2006; 94(9): 1351 .

[46] Hardell L, Hansson Mild K, Kundi M. Re: "Long-term mobile phone use and brain tumor risk". Am J Epidemiol 2005; 162(6): 600-1.

[47] Hardell L, Hansson Mild K. Re: "cellular telephone use and risk of acoustic neuroma". Am J Epidemiol 2004; 160: 923.

[48] Kundi M. Re: "cellular telephone use and risk of acoustic neuroma". Am J Epidemiol 2004; 160: 923-4.

(C) Hardell et al.; Licensee Bentham Open.

This is an open access article distributed under the terms of the Creative Commons Attribution License (http://creativecommons.org/license/by/2.5/), which permits unrestrictive use, distribution, and reproduction in any medium, provided the original work is properly cited. 